\title{
Plastic Surgeons and COVID-19 Pandemic
}

Suvashis Dash' Rojaleen Das² Shivangi Saha' Maneesh Singhal'

\begin{abstract}
Address for correspondence Maneesh Singhal, MS, Mch, Room no. 223, Office of the Head of Department, Plastic Reconstructive and Burns Surgery, Jai Prakash Narayan Apex Trauma Centre, AlIMS New Delhi, Safdarjung Enclave, New Delhi, Delhi 110029, India (e-mail: drmaneesh@gmail.com).
\end{abstract}

Indian J Plast Surg:2020;53:191-197

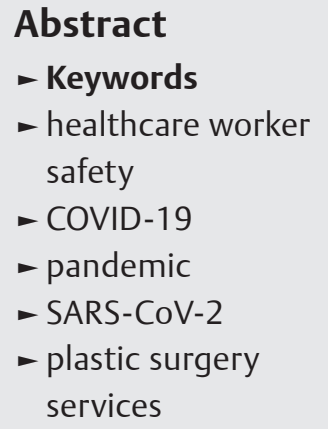

The world is suffering from the unprecedented problem of the COVID-19 pandemic. As healthcare professionals, we face the imminent danger of exposure. For Plastic, Reconstructive and Burn surgeons, safety and smooth functioning of day-to-day work during this pandemic is of the utmost priority. However, it is also our responsibility to stop the human-to-human transmission chain and conserve the medical resources for rational use. The disease has spread throughout the country, and with the number of infections increasing day by day, it is very important to adhere to the safety principles. This document aims to provide some insights into the world of plastic, reconstructive and burn surgeons in the time of the COVID-19 outbreak.

\section{Background}

The world is suffering from an unprecedented problem in the form of the COVID-19 pandemic. ${ }^{1}$ As healthcare professionals, we are facing the imminent danger of exposure to this disease. It is therefore essential for plastic surgeons to keep themselves safe while trying to resume standard practices in the due course of time.

This document aims to provide some insights into plastic surgery practices during the time of the COVID-19 outbreak. We intend to offer our services to the maximum people while conserving the medical resources for an upcoming crisis. ${ }^{2}$ Amidst the pandemic, every patient should be treated as a COVID-19 suspect irrespective of the status of the test because of the long window period, and nearly 70 to $80 \%$ of the population being asymptomatic or having minor symptoms. ${ }^{3,4}$ They may present to the health facility for any emergency or outpatient service. Clinical evidence is evolving, and new information is being added every day. However, there is enough evidence which shows that surgical procedures and patient interactions are one of the most common modes of disease transmission. This article highlights the practical aspects pertaining to plastic surgery services during the time of the pandemic followed by advice to plastic surgeons.

\section{General Challenges about Surgical Specialties and COVID-19}

- Asymptomatic COVID-19 infections account for more than 70\%; hence, operating in apparently healthy patient also carries a potential risk to healthcare worker. ${ }^{4}$

- A healthy patient many encounter SARS-CoV-2 from healthcare worker or copatients.

- Pooling the resources and workforce for the pandemic.

- Intensive care and availability of the mechanical ventilators for postoperative cases may be difficult too, as they are earmarked for COVID-19 patients. ${ }^{5}$

- Patients with comorbidities and elderly are at a higher risk for severe disease; the decision to operate has to be balanced with the risk of infection and cross infection. ${ }^{6}$

\section{Challenges Faced by Plastic Surgeons and the System}

- To provides the best possible care to all patients within the constrained resources and human resources.

- Protection of self and family from infection.

- Protection of team members and other patients from infection.
License terms

()(1) $\Theta \circledast$ 
- To support medical, nursing and administrative teams also engaged in taking care of COVID-19 patients.

\section{Self-Protection and Infection Control}

Protecting oneself from infection is a priority because we can transmit the infection to other patients. Simple steps like separate hospital clothing and footwear, avoiding accessories such as watch, finger rings, waist-belts, tying hair neatly, and coming clean shaven to work, are vital in infection control. One should wear a face mask at all times in the hospital. A separate pair of spectacles for the hospital is advisable and avoid using contact lenses. Use transparent "Clean Go" covers for mobile phones to avoid contamination. Hand hygiene at every step is a critical element of preventing infections to self and team members and other patients.,

Avoid bringing hospital equipment home, leave them at the hospital. Inform family members before reaching home, so that they can open the front door and you can enter without touching doorknobs and bells, sanitize shoes with surface disinfectant. Place accessories such as pen, key, etc. in a container and sanitize them, clean the container too. Disinfect phones by surface disinfectant. Go for a bath immediately, and do not touch any family member or any surface. Make sure to wash all the clothes properly. ${ }^{5,7}$

\section{Plastic Surgery Services}

\section{Patient Interaction}

All nonemergency patient interactions may only be done after teleconsultations (audio/video) to assess the actual need for meeting the patient. During in person interaction with the patients, maintain adequate distancing and wear a mask. One should wear a pair of gloves to prevent direct contact with the patients. Avoid touching face with a gloved hand. Use a second pair of gloves over the first pair while doing a patient examination. Discard the second pair of gloves after the examination; this will avoid cross-infection. Sanitize or wash the gloved hands regularly. Cover head with a cap and use face shield while examining areas like head, neck and oral cavity or while engaging in any aerosol-generating procedures. Patient interaction and photography sessions should be kept brief. Use new case sheets while documenting, although digital documentation is preferred. Clean the areas after each session of patient visits. If the institutional policy allows, a written disclaimer should be obtained from the patient, mentioning that he/she understands the risks of visiting the healthcare premises, which is a high-risk zone. ${ }^{7.8}$ At the first consultation itself, the patient's case should be discussed with the senior-most team member to make a definitive decision and reduce or even obviate the need for repeated patient visits.

\section{Support System and Resources}

Rationalize the use of personal protection equipment (PPE). Leave the PPE for colleagues directly involved in COVID-19 care. Staggering of duties or a rotation system is a useful way for the avoidance of overcrowding and helpful for resource management. Earmarking of selected areas as "contamination zone," "potential contamination zone," and "clean zone" is necessary to control infection. Screening of individuals for COVID-19 as per hospital protocol is vital. ${ }^{7,9}$

Training of healthcare personnel about disease transmission, hand washing, donning, doffing and knowledge about screening is essential. Sharing video demonstrations is useful for the same. ${ }^{10,11}$ The protocol for disinfection of specific areas of speculated high-contamination should be done by using a surface disinfectant.

\section{Wards}

Training of the staff regarding the maintenance of at least $2 \mathrm{~m}$ of distance between between beds and isolation of high-risk patients (although this may lead to a reduction in bed number). Hand hygiene and sanitization procedures of specialized equipment as well as hallways, corridors and lifts should be well disseminated and discussed. If adequate space is available, then a separate facility for high-risk individuals such as patients with comorbidities, systemic diseases and elderly can be placed. Limit patient attendants, except for small children, in which case restrict the caretakers, if possible. ${ }^{11,12}$

\section{Office}

Staff management in this time is important, protecting high-risk staff from the infection by decreasing exposure is necessary. Most of the communications and notices can be served via electronic media. Rotation policy for staff decreases overcrowding and exposure. ${ }^{11,12}$

\section{Operation Rooms}

The surgery should proceed in an OT complex with separate entries and exits, with separate air conditioning facility. Even when two to three surgeons operate, the PPE requirement goes upto 10 to 14 in number, depending upon the anesthetists, floor and scrub nurses, OT technicians, OT attendants, and cleaning and support staff. Hence, judicious resources management should be kept in mind. The linens used in surgery ideally should be disposable. Full PPE, including $\mathrm{N} 95$ face mask and the face shield, is a must during surgery. ${ }^{13}$ Operating with the face shield has problems such as intense fogging, breathing issues, and difficulty in accommodating the loupes.

OT complex should have a clear-cut area for donning and doffing, and one/two dedicated operating rooms (ORs) for COVID-19/COVID-19 suspect patients' needs to be created/ identified. This new area should have all the furniture and trolleys marked for COVID-19. A separate route for transferring COVID-19 patients, including earmarked lifts (separate from lifts for staff transfer), should be designed. ${ }^{12,13}$ Every patient undergoing emergency surgery should be considered a COVID-19 suspect and receive appropriate care with all necessary precautions irrespective of the status of the test and its report. Important points to consider is to limit the exposure time and the number of staff inside the OR. All the standard precautions are to be followed stringently. For rational PPE use and increase in speed of surgery, a person of reasonable 
seniority should be designated to operate. It is also vital to reduce the aerosol-generating procedures, for example, intubation, tracheostomy, maxillofacial and other intraoral surgeries; use of rotatory power tools during K-wire and plate fixations have also been documented as aerosol-generating. ${ }^{14,15}$ Now, we are aware that SARS$\mathrm{CoV}-2$ virus stays in the environment for as long as 9 days, so these procedures need extra precautions. ${ }^{16}$

Along with the complete PPE. which includes N95 respirator, gown, shoe, head cover and surgical gloves, the face shield is mandatory. ${ }^{10,17}$ It is important to disinfect the OR postsurgery. Positive pressure ventilation during the procedure should be avoided..$^{18}$ Use of regional anesthesia, if adequate, should be encouraged in place of general anesthesia to prevent potential aerosol generation. ${ }^{19}$

\section{Preoperative Screening}

Do we need to test all the patients who are planned to undergo surgical procedures? Indian Council of Medical Research (ICMR) and Government of India have updated the testing strategy many times; to date, none of the versions has recommended testing for patients planned for elective surgeries. False negatives rates of RT PCR have been reported to be as high as 10 to $30 \%$. So, retesting in negative patients might be considered if symptoms persist. ICMR reports that approximately $70 \%$ of infected individuals either have no symptoms or very mild symptoms, while among potential contacts, only $5 \%$ test positive. ${ }^{20,21}$ With testing, the healthcare professional will be safer, PPE use can be used rationally, and segregation of COVID and non-COVID cases into different areas can be done. On the contrary, the testing has some shortcomings, such as shortage of testing capacity and resources in comparison to the present population in the country, cost of screening each patient will add monetary burden, and it may give a false sense of security and increase the chance of infection due to lapse in infection control protocols.

Patients requiring urgent plastic surgery procedures and matching the fever, travel, occupation, contact and clustering (FTOCC) guidelines must be screened. The person's sample should be immediately sent, and one may proceed for surgery based on the clinical requirement, without waiting for the result. We feel the COVID-19 screening should be done in all the cases before surgery, but this has to be on the basis of the individual policy of the healthcare facility, capacity and local disease burden.

\section{Risk Stratification}

With sound screening techniques and adequate PPE, in the form of mask and face shield, some elective surgeries can be taken up. While taking cases for surgery, consider factors such as capacity of setup, manpower, resources, patient comorbidity, age and clinical rationality of the procedure ( - Table 1 ). The operative list should be prioritized on a day-to-day basis ${ }^{18,22}$ ( - Fig. 1).

\section{Specific Points Related to Individual Sub-Specialties}

\section{Hand Surgery and Trauma ${ }^{23}$}

1. Use of regional anesthesia and wide awake local anesthesia no tourniquet technique (WALANT) should be encouraged.

2. Defer all the elective procedures. If possible, use day care surgery.

3. Reduce frequent postoperative follow-ups by using absorbable sutures and minimal dressing care.

4. Postoperative physiotherapy should be done via teleconsultation.

5. For hand fractures, if possible closed reduction and splinting to be used instead of drilling and K-wires.

\section{Burns and Reconstruction ${ }^{24}$}

1. Emergency burn care should run as usual.

2. Admitted burn patients with fever should be tested for COVID-19 if corresponding indicators are present.

3. Diet should only be taken from the hospital.

4. Avoid tracheostomy if not emergent and life-saving.

5. Separate air handling units for ICU/HDU and other areas.

6. Conservative management for mild burns.

7. Use tissue glue instead of staples or sutures to reduce patient visits.

8. Home-based smaller burn dressing with telemedicine support.

9. Defer chronic burn reconstruction, if possible.

\section{Microsurgery ${ }^{25}$}

1. Free flaps procedure to be avoided; it is only to be done when other options do not solve the problem.

2. Osteocutaneous flaps should be avoided in view of high-aerosol formation and contamination during the use of cutting power tools.

3. Use the regular workhorse flaps for reconstruction and avoid atypical flaps.

4. Use sutures and clips, preferably over cautery.

5. The senior-most surgeon should perform the critical steps to minimize complication and operative time.

\section{Maxillofacial Surgery ${ }^{18}$}

1. Use scalpel preferably over cautery, and if the latter is to be used, utilize minimal power setting.

2. Drilling to be done at the lowest power with limited irrigation.

3. Use intermaxillary fixation (IMF) for stable fractures without much displacement in mandible and midface.

4. Osteotomes should be used, preferably over power drills. 
Table 1 Risk stratification of surgeries (Adapted from the American College of Surgeons ${ }^{22}$ )

\begin{tabular}{|l|l|l|}
\hline & Categories & Suggestions \\
\hline A. & $\begin{array}{l}\text { Patients with chronic or stable problems, for exam- } \\
\text { ple, postburn contractures, congenital anomalies, } \\
\text { syndactyly, secondary surgeries of cleft lip and palate } \\
\text { hemangiomas }\end{array}$ & $\begin{array}{l}\text { Should be postponed. However, due to issues related to inadequate } \\
\text { speech development, palate procedure maybe done to avoid speech } \\
\text { problems }\end{array}$ \\
\hline B. & $\begin{array}{l}\text { Patients with problems of wounds and post-traumatic } \\
\text { reconstructions such as skin grafting, flap coverage } \\
\text { operation, exposed tissue expanders }\end{array}$ & $\begin{array}{l}\text { Should be done under regional and spinal anesthesia rather than gen- } \\
\text { eral anesthesia. } \\
\text { Transfer to a facility where adequate manpower and clear segregation } \\
\text { of COVID and non-COVID patient is present should be considered. } \\
\text { When immediate transfer facility is not possible, then minimal possible } \\
\text { intervention as per resources available should be considered to buy } \\
\text { time till transfer }\end{array}$ \\
\hline C. & $\begin{array}{l}\text { Patients with active cancers needing postablation } \\
\text { reconstruction/burn patients needing grafting for sepsis } \\
\text { control/exposed implants with systemic infections }\end{array}$ & $\begin{array}{l}\text { Should not be postponed and operated early. However, they should be } \\
\text { done with all precautions } \\
\text { Units should be triaging the patients as per the clinical need }\end{array}$ \\
\hline D. & $\begin{array}{l}\text { Non limb-threatening injuries, nerve injuries, tendon } \\
\text { injuries }\end{array}$ & $\begin{array}{l}\text { Should be operated considering other operative lists or rescheduling } \\
\text { with other cases } \\
\text { Local anesthesia, nerve blocks, WALANT preferred }\end{array}$ \\
\hline E. & $\begin{array}{l}\text { Acute limb-threatening surgery replantation or critical } \\
\text { revascularizations, constriction ring syndrome causing } \\
\text { edema and imminent gangrene are acute emergency } \\
\text { conditions }\end{array}$ & $\begin{array}{l}\text { Should be given priority over all other surgeries, except immediate } \\
\text { lifesaving surgeries }\end{array}$ \\
\hline F. & $\begin{array}{l}\text { Cosmetic surgery/nonsurgical aesthetic procedures/ } \\
\text { minor surgical procedures scar revisions }\end{array}$ & $\begin{array}{l}\text { Should be postponed until control of the pandemic, except for man- } \\
\text { agement of complications of earlier procedures, which need to be } \\
\text { addressed early }\end{array}$ \\
\hline
\end{tabular}

Note: Exploration in case of failing free flaps/replantation should be discussed with the team and decision should be taken considering the condition.

Abbreviation: WALANT, wide awake local anesthesia no tourniquet technique.

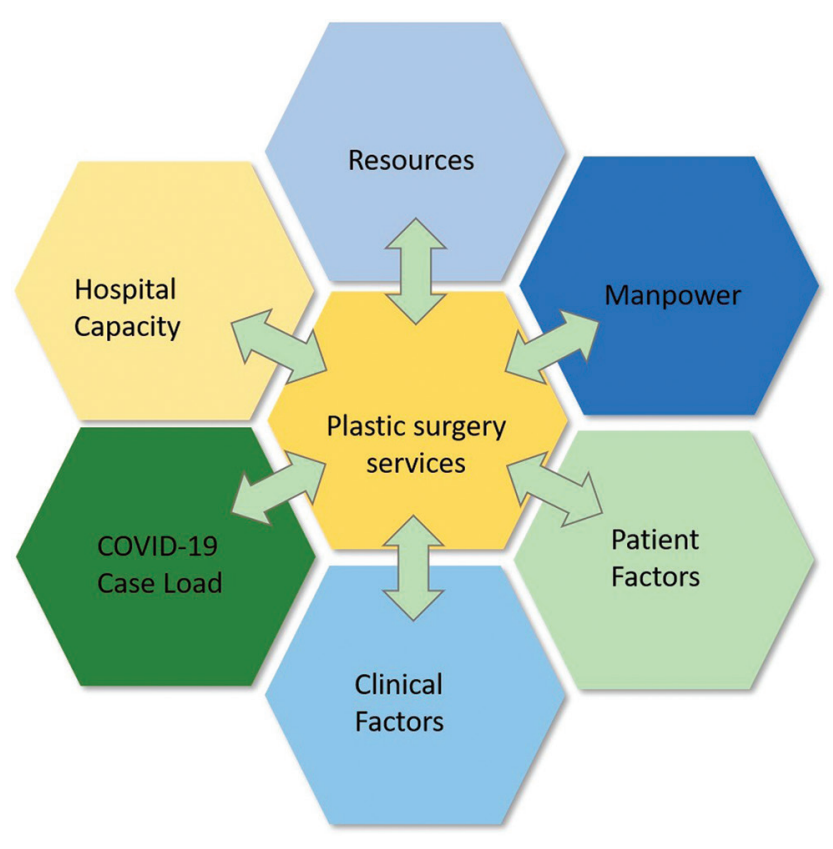

Fig. 1 Showing the critical factors to consider for maintenance of plastic surgery services during COVID-19 pandemic.

\section{Cosmetic Surgery ${ }^{26}$}

1. It is advised that these procedures should be avoided until the pandemic is controlled
2. Patients with complications, for example, exposed implants and skin necrosis, should be addressed immediately.

\section{Physiotherapy ${ }^{27}$}

1. Minimize the nonessential patient visits.

2. Social distancing among patients during visits.

3. Strict no sharing policy of physiotherapy equipment such as bands, balls, tubing and weights until sanitized. The patient should use the equipment by wearing gloves.

4. Videos concerning different exercises help in avoid multiple visits.

\section{PPE Equipment with Special Consideration to Plastic and Microsurgery}

We all know that the pandemic is going to stay for some time, therefore we have to reassess our strategy for operating. We have to adapt to using PPEs during clinical work, although it causes great inconvenience. Itching, skin eruptions, shortness of breath, fogging, and vision problems have been reported with PPE use.

Special point considerations for the use of protective goggles, visors or face shields and PPE are as follows:

1. Protective goggles cause fogging by air expired from the mask-for reduction, use a properly fitted mask or use adhesive tape over the mask to fix it to the nose. A preoperative mask fitting test should be done. 
2. The other problem with goggles, which do not have exit ports, are fogging due to sweat and evaporation. This problem can be solved by making a few small ports on each side.

3. Face shields and visors are better in terms of fogging prevention. However, when the masks' opening port is near to face shield, it may fog.

4. Microsurgery using N95, goggles or face shield is challenging, due to recurrent fogging; also, uncomfortable position of the loupe is distracting and tiring. Cutting holes in the face shield to fit the loupe is an option, but the fitting should be adequately sealed.

5. There are large face shields available for the accommodation of the loupe and light source. Alternatively, the light source can be placed over the head.

6. Using a microscope with PPE is troubling. In this scenario, the surgeon should use full PPE and N95 mask and then use the microscope. The patient should be draped wholly, only the operating field should be kept open.

Handling dressing material and dressing for COVID-19 suspect or confirmed patients should be done using PPE. ${ }^{11}$ Wound drains and other tubes are to be managed very carefully, minimizing exposure to body fluid. Proper biomedical waste handling and disposal should be done to prevent further transmission of the disease. ${ }^{28}$

\section{Few Practice Points at the Time of Surgery}

- Face shields can be customized to adjust the loupes and light sources by making a hole in the shield and fitting loupes in an airtight manner.

- During the use of drills, a transparent sheet can be used to cover the working area to reduce splashing and contamination.

- The most experienced surgeon should perform the critical steps to optimize outcome and decrease the operating time.

- During anastomosis near the head and neck area, all the exposed aerodigestive tract should be securely covered, while monitoring the patient vigilantly.

- Minimal use of monopolar cautery in low power settings, and fixing a small suction tube over the cautery, will reduce the surgical smoke.

- Minimizing the personnel inside OT during intubation, extubation, and tracheostomy. ${ }^{29}$

- While using an operating microscope, keep the maximum part of the microscope covered with adhesive sterile disposable sheets.

\section{Biomedical Waste Management ${ }^{27}$}

- Anatomical wastes such as debrided and discarded tissues-yellow bins.

- Soiled dressings-yellow bins.

- Disposable plastics-red bin for autoclaving and then shredding and recycling.
- General waste-black/green bin as per biodegradability.

- Positive cases-waste from COVID-19 confirmed cases should go to yellow bin.

- PPEs should go to yellow bin for incineration.

- Waste which is suspicious should be collected in double-layered yellow bags with proper labeling.

\section{Teaching, Training and Academics}

The online format, although it seems apt for the moment and convenient, cannot replace the assessment of bedside skills that are quintessential to clinicians. The e-learning format has brought the entire plastic surgery community closer, where residents can get access to lectures from the doyens of the field at the click of a button. The virtual grand rounds, clinical case discussions, surgical vignettes, and videos from the experts are invaluable resources. The teaching and training activities are definitely getting a backseat during the chaos of the pandemic. Although the utilization of online teaching and learning modes are provided as alternatives, we will need some time to get accustomed to these means. We may expect many academic activities, including a conference in the future, to be held via massive online platforms. ${ }^{30,31}$

\section{Research Considerations}

During this period, the research front is on full throttle, from molecular and genetic studies and pathogenesis to treatment and vaccine studies. From a plastic surgery point of view, many fronts on the COVID-19 related issues possess avenues for further research. The newer problems demand innovative solutions. ${ }^{32}$ In plastic surgery with COVID-19, research on pressure sore during extended ventilatory support of COVID-19 patients and solution for this problem, PPE-related skin trauma, wounds with respect to viral load, etc. will possibly be new avenues of research.

\section{Conclusion}

The situation is continually changing with respect to the burden of disease and the number of cases. Workforce irrespective of specialties will be allocated to designated COVID-19 care when necessary. In the countries where the load of the epidemic is very high, for example, in the USA, the White House has also requested the American Society of Plastic Surgeons to contribute and donate PPE and ventilators. The plastic surgeons should be updated and trained with essential knowledge and care about this condition as well as infection prevention and control. During this period, use of online classes and webinars is fruitful in the continuation of education for young plastic surgery trainees. The suspected or confirmed and close contacts with confirmed COVID-19 cases should be notified to concerned authorities without any delay. Slowly, we have to learn and adapt how to live and grow through a pandemic. 


\section{Key Points}

- Prioritization of operative cases and judicious use of resources are essential.

- Infection control and protection of self and coworkers should be the priority.

- A disclaimer informing the associated risk of contracting COVID-19 from hospital visit should be obtained from the patient.

\section{Source(s) of Funding}

None.

\section{Conflicts of Interest}

None declared.

\section{References}

1 WHO. WHO announces COVID-19 outbreak a pandemic. Available at: https://www.who.int/emergencies/diseases/novel-coronavirus-2019/events-as-they-happen. Accessed March 27,2020

2 Coronavirus situation reports. Available at: https://www. who.int/docs/default-source/coronaviruse/situation-reports/ 20200326-sitrep-66-COVID-19.pdf?sfvrsn=81b94e61_2. Accessed March 27, 2020

3 Huang C, Wang Y, Li X, et al. Clinical features of patients infected with 2019 novel coronavirus in Wuhan, China. (published correction appears in Lancet. 2020 Jan 30) Lancet 2020;395(10223) :497-506

4 Lauer SA, Grantz KH, Bi Q et al. The incubation period of Coronavirus disease 2019 (COVID-19) from publicly reported confirmed cases: estimation and application. Ann Intern Med 2020;172(9):577-582

5 Wong J, Goh QY, Tan Z, et al. Preparing for a COVID-19 pandemic: a review of operating room outbreak response measures in a large tertiary hospital in Singapore. Can J Anaesth/ Journal Canadien D'anesthésie 2020;67(6):732-745

6 Li B, Yang J, Zhao F, et al. Prevalence and impact of cardiovascular metabolic diseases on COVID-19 in China. Clin Res Cardiol 2020;109(5):531-538

7 Lai TH, Tang EWH, Chau SKY, Fung KSC, Li KK. Stepping up infection control measures in ophthalmology during the novel coronavirus outbreak: an experience from Hong Kong. Graefes Arch Clin Exp Ophthalmol 2020;258(5):1049-1055

8 Lui RN, Wong SH, Sánchez-Luna SA, et al. Overview of guidance for endoscopy during the coronavirus disease 2019 pandemic. J Gastroenterol Hepatol 2020;35(5):749-759

9 World Health Organization, Rational Use of Personal Protective Equipment for Coronavirus Disease (COVID-19): Interim Guidance, 27 February 2020. Geneva, Switzerland: Wo r ld Health Organization; 2020

10 CDC. PPE training. Available at: https://www.cdc.gov/vhf/ ebola/hcp/ppe-training/index.html. Accessed March 27, 2020

11 CDC. Information for healthcare professional. Available at https://www.cdc.gov/coronavirus/2019-ncov/healthcarefacilities/index.html. Accessed March 27, 2020

12 Infection prevention and control guidance for pandemic coronavirus. Available at: https://assets.publishing.service.gov.uk/government/uploads/system/uploads/ attachment_data/file/893320/COVID-19_Infection_ prevention_and_control_guidance_complete.pdf. Accessed March 27, 2020

13 Forrester JD, Nassar AK, Maggio PM, Hawn MT. Precautions for operating room team members during the COVID-19 pandemic. J Am Coll Surg 2020;230(6):1098-1101

14 van Doremalen N, Bushmaker T, Morris DH, et al. Aerosol and surface stability of SARS-CoV-2 as compared with SARSCoV-1. N Engl J Med 2020;382(16):1564-1567

15 Hsieh TY, Dedhia RD, Chiao W, et al A guide to facial trauma triage and precautions in the COVID-19 pandemic. Facial Plastic Surgery \& Aesthetic Medicine2020;(e-pub ahead of print). doi: https://doi.org/10.1089/fpsam.2020.0185

16 Kampf G, Todt D, Pfaender S, Steinmann E. Persistence of coronaviruses on inanimate surfaces and their inactivation with biocidal agents. J Hosp Infect 2020;104(3):246-251

17 CDC. Protecting healthcare personnel. available at https:// www.cdc.gov/hai/prevent/ppe.html. Accessed March 27, 2020

18 Royal College of Surgeons of England. Updated Intercollegiate General Surgery Guidance on COVID-19. Available at: https:// www.rcseng.ac.uk/coronavirus/joint-guidance-for-surgeons-v2/. Accessed March 27, 2020

19 Lie SA, Wong SW, Wong LT, Wong TGL, Chong SY. Practical considerations for performing regional anesthesia: lessons learned from the COVID-19 pandemic. Can J Anaesth/ Journal Canadien D'anesthésie 2020;67(7):885-892

20 ICMR. Revised Strategy for COVID19 testing in India (Version 4). Available at: https://www.icmr.gov.in/cteststrat.html. Accessed June 26, 2020

21 Gandhi M, Yokoe DS, Havlir DV, Asymptomatic transmission, the Achilles' Heel of current strategies to control Covid-19. N Engl J Med 2020 (e-pub ahead of print). doi: https://www. nejm.org/doi/full/10.1056/NEJMe2009758

22 American College of Surgeons. COVID-19: Elective Case Triage Guidelines for Surgical Care. Available at: https://www.facs. org/COVID-19/clinical-guidance/elective-surgery. Accessed March 27, 2020

23 Ducournau F, Arianni M, Awwad S, et al. COVID-19: Initial experience of an international group of hand surgeons. Hand Surg Rehabil 2020;39(3):159-166

24 Barret JP, Chong SJ, Depetris N, et al. Burn center function during the COVID-19 pandemic: An international multi-center report of strategy and experience. Burns 2020; (e-pub ahead of print). doi:10.1016/j.burns.2020.04.003

25 RCSI. Guidelines for microsurgery during the COVID19 pandemic. Available at: https://www.rcsi.com/ dublin/-/media/feature/media/download-document/ dublin/covid-19-section/surgical-practice/other-national-clinical-programmes-and-recognised-bodies/ irish-microsurgery-special-interest-group-guidelines-for-microsurgery-during-the-covid-19-pandemic. $p d f+\& c d=1 \&$ hl= en\&ct=clnk\&gl=in. Accessed June 26, 2020

26 Hongkong Tatler. Cosmetic surgery during the Coronavirus pandemic: is it safe? Available at: https://hk.asiatatler.com/ style/cosmetic-surgery-coronavirus-covid. Accessed June 26, 2020

27 Thomas P, Baldwin C, Bissett B, et al. Physiotherapy management for COVID-19 in the acute hospital setting: clinical practice recommendations. J Physiother 2020;66(2):73-82

28 Central Pollution Control Board. Bio-Medical-Waste guidelines. Available at: https://www.cpcb.nic.in/uploads/Projects/ Bio-Medical-Waste/BMW-GUIDELINES-COVID.pdf. Accessed March 27, 2020 
29 Brewster DJ, Chrimes NC, Do TB, et al Consensus statement: Safe Airway Society principles of airway management and tracheal intubation specific to the COVID-19 adult patient group. Med J Aust 2020 (e-pub ahead of print). doi: https://www.mja. com.au/journal/2020/212/10/consensus-statement-safe-airway-society-principles-airway-management-and

30 MOHFW. SOP for reallocation of residents/PG students and nursing students as part of hospital management of COVID. Available at https://www.mohfw.gov.in/pdf/COVID19SOPfordoctorsand nurses.pdf. Accessed March 27, 2020
31 Moszkowicz D, Duboc H, Dubertret C, Roux D, Bretagnol F. Daily medical education for confined students during COVID19 pandemic: A simple videoconference solution. Clin Anat 2020;(e-pub ahead of print). doi:10.1002/ca.23601

32 World Health Organization. Global research on coronavirus disease (COVID-19). Available at: https://www.who.int/ emergencies/diseases/novel-coronavirus-2019/global-research-on-novel-coronavirus-2019-ncov. Accessed June 3, 2020 